\title{
5 Research Square

\section{Amyloidosis in major body organs examined during autopsies at Mbarara Regional Referral Hospital}

Jeremy Menya Kirunda ( $\sim$ jeremykirunda58@gmail.com )

Mbarara University of Science and Technology Faculty of Medicine https://orcid.org/0000-0003-44481195

\section{Joseph Bruno Mudde}

Mbarara University of Science and Technology Faculty of Medicine

\section{Brenda Faith Musibika}

Mbarara University of Science and Technology Faculty of Medicine

\section{Musema Kizito}

Mbarara University of Science and Technology Faculty of Medicine Ibrahim Gubya

Mbarara University of Science and Technology Faculty of Medicine

\section{Raymond Atwine}

Mbarara University of Science and Technology Faculty of Medicine Abraham Birungi

Mbarara University of Science and Technology Faculty of Medicine

Paddy Behayo

Kyambogo University

\section{Frank Ssedyabane}

Mbarara University of Science and Technology Faculty of Medicine

\section{Research}

Keywords: Amyloidosis, Autopsies, Organs, Brain, Heart, Kidney, Liver

Posted Date: August 5th, 2021

DOI: https://doi.org/10.21203/rs.3.rs-764285/v1

License: (c) (i) This work is licensed under a Creative Commons Attribution 4.0 International License. Read Full License 
Amyloidosis in major body organs examined during autopsies at Mbarara Regional Referral Hospital

Jeremy Kirunda Menya ${ }^{\mathbf{1}}$, Mudde Joseph Bruno ${ }^{\mathbf{1}}$, Musibika Faith Brenda ${ }^{\mathbf{1}}$, Musema Kizito ${ }^{\mathbf{1}}$, Gubya Ibrahim ${ }^{\mathbf{1}}$, Atwine Raymond ${ }^{2}$, Birungi Abraham ${ }^{2}$, Behayo Paddy ${ }^{2}$ and Ssedyabane Frank ${ }^{\mathbf{1}}$

${ }^{1}$ Department of Medical Laboratory Science, Mbarara University of Science and Technology (MUST), P. O. Box 1410 Mbarara Uganda

${ }^{2}$ Department of Pathology, Mbarara University of Science and Technology, P. O. Box 1410 Mbarara Uganda

\section{Corresponding Author}

Jeremy Kirunda Menya, BMLS (MUST), P. O. Box 1410 Mbarara, Uganda

Email: jeremykirunda58@ gmail.com, Telephone: +256-786953438/+256-754353071

Number of words: 3613

Number of pages: 15

Number of tables: 3

\section{ABSTRACT}

\section{Background}

Amyloidosis is an infrequent disease that occurs when an abnormal protein, called amyloid, deposits in body organs and disrupts their normal function. Amyloid is not normally found in the body but it can be formed from several different types of protein. Commonly affected organs include the heart, kidneys, gastrointestinal (GI) tract/liver or the peripheral or autonomic nervous system (NS). Amyloidosis can lead to diseases such as Alzheimer's disease, spongiform encephalopathies and diabetes mellitus type 2 .

\section{Main objective}

To establish the prevalence of amyloidosis in major body organs examined during autopsies at Mbarara regional referral hospital and to correlate cause of death with amyloidosis.

\section{Methods}

Brain, heart, kidney, and liver samples were obtained from 23 bodies during autopsies at Mbarara Regional Referral Hospital which were then processed to produce 2 slides per tissue of 
each of the above organ samples. These slides were then stained using H\&E and Congo red staining protocols and then examined for amyloidosis under the light microscope.

\section{Results}

The mean age of the bodies was 61.26 of which 5 (21.7\%) were female while $18(78.3 \%)$ were male. 3 bodies (13.0\%) tested positive for amyloidosis in the kidney; 2 males (8.70) and 1 female (4.35). All the other organs tested negative.

\section{Conclusion}

In our study, body organ investigation revealed amyloid in the kidney of 3 bodies. The prevalence of amyloidosis was $13 \%$ therefore amyloidosis diagnosis ought to be put into consideration at Mbarara Regional Referral Hospital.

Key words: Amyloidosis; Autopsies; Organs; Brain; Heart; Kidney; Liver.

\section{INTRODUCTION}

Amyloidosis is a diverse group of disorders in which there is extracellular deposition of abnormal protein fibrils in different body organs depending on the type of protein (1). Amyloid fibrils penetrate organs and tissues and deposit there leading to swelling and progressive loss of function (2). In naming amyloidoses, the letter A is used to designate amyloid followed by an abbreviation of the name of the protein fibril (3). The amyloidoses vary depending on the type of protein undergoing aggregation, the organs in which they deposit and in their clinical features (4).

The global burden of amyloidosis is difficult to define due to the fact that in many places around the world, the disease is misdiagnosed or underdiagnosed and there are few studies that have reliable data (5).

A cross sectional study in Egypt found the prevalence of amyloidosis in Rheumatoid Arthritis patients to be 4 out of 30 patients (13.3\%). This study was carried out by obtaining abdominal fat aspiration biopsies from these patients and confirming amyloid presence by Congo red staining (6).

In Uganda, an autopsy study revealed the incidence of amyloidosis to be $0.57 \%$. This study was done by re-examining haematoxylin and eosin sections from autopsy archives at Mulago hospital, Kampala over a 23-year period. Amyloid presence was then confirmed by Congo red staining (7). 
Amyloidosis diagnosis is based on confirmation of presence of deposits of these abnormal proteins in tissues. Biochemical markers such as Brain Natriuretic Peptide (BNP) type B, N-terminal-proBNP and troponins are available but not routinely used and are still under study $(8,9)$.

Congo red stain is the gold standard for detection of the presence of amyloid fibrils. Under a light microscope, deposits of amyloid stained with Congo red typically have an orange to red colour. Congo red stain should be used to confirm a suspicion and to rule out the possible presence of early amyloid deposits, which are not easily seen in hematoxylin-eosin. (9).

This study also aimed at knowing the burden of amyloidosis in south-western Uganda which will increase its clinical suspicion, diagnosis and treatment.

\section{METHODS}

\subsection{Setting}

The study was carried out in the pathology department of Mbarara Regional Referral Hospital (MRRH). MRRH is located in Mbarara district, south western Uganda. It is approximately $260 \mathrm{~km}$ from Kampala, the capital city of Uganda and $2 \mathrm{~km}$ from the town centre on the MbararaKabale highway. MRRH is a public institution and is the regional referral hospital of south western Uganda with a capacity of 1200 beds. The MRRH mortuary and histopathology laboratory were chosen because they receive clients from the entire western region of Uganda; hence the sample size was representative of a big number of Ugandans.

\subsection{Data Collection}

Any dead body of 40 years and above received at a MRRH mortuary in Western Uganda for which an autopsy was requested was included in the study unless it had started decomposing, it was missing critical information such as age, death was due to a highly infectious disease or the relatives did not consent to an autopsy.

23 bodies which suited our inclusion criteria were dissected to obtain brain, liver, kidney and heart tissues which were immersed in 10\% neutral buffered formalin in a 1:20 ratio to preserve them. When the tissues were ready to be processed, they were macroscopically examined and small pieces were cut out and placed in tissue cassettes.

Microtomy was performed and tissue sections of $3 \mu \mathrm{m}$ were obtained, and stained with the Haematoxylin and Eosin stain and Congo red staining method. The Haematoxylin and Eosin 
staining method involved dewaxing and hydrating sections, staining in haematoxylin for 1 minute, blueing for 3 minutes, staining in Eosin for 1 minute, dehydrating through increasing concentrations of alcohol, clearing in xylene and mounting with DPX. The Congo red staining method involved dewaxing and then hydrating sections, staining for 1-5 minutes in 50\% alcoholic Congo red, differentiating 1-3 minutes in $0.2 \% \mathrm{KOH}$ in $80 \%$ alcohol, rinsing in tap water, counter staining for 2-8 minutes with alum haematoxylin, washing in tap water, dehydrating quickly through alcohol, clearing in xylene and mounting with DPX.

Information such as age, sex, address and cause of death were obtained as well and filled in a data collection form.

\section{RESULTS}

The study enrolled 23 bodies, of which the age group of $60-69$ years had the highest number of bodies constituting $47.8 \%$ (11/23). Male bodies were more than female bodies constituting $78.3 \%(18 / 23)$ and $21.7 \%$ (5/23) respectively. Most of the bodies were from people residing in the urban areas of Mbarara municipality, and these constituted 30.4\% (7/23) of the whole study population. Other areas where bodies came from included; Masaka district, Rukungiri district, Kiruhura district and Ibanda district, each constituting $4.3 \%$ (1/23). Table 1.

From our study, we found that only 3 bodies provided tissues which were positive with the Congo red stain. This made the general prevalence of amyloidosis to be $13 \%(3 / 23)$. Table 2

From all the harvested tissues, all those found to be positive with Congo red stain were kidneys. This meant that the kidney had the highest prevalence by organ (100\%). On further analysis, two of the positive kidney samples had been harvested from a male body, while only one had been harvested from a female body. This put our prevalence of amyloidosis by gender to be $66.7 \%$ and $33.3 \%$ respectively. Table 2 .

We also found out that the bodies whose causes of death were Secondary peritonitis, Asphyxia secondary to aspiration pneumonitis and Bronchopneumonia each had one case of Congo red positive kidney tissue. There was no significant correlation between cause of death and amyloidosis. Bronchopneumonia showed a positive but non-significant correlation with 
Amyloidosis (Spearman's rho 0.1629, Prob > $|\mathrm{t}|$ 0.4577) as well as Secondary peritonitis $\begin{array}{lllllll}\text { (Spearman's } & \text { rho } & 0.3386, & \text { Prob } & > & |t| & 0.1140) \text {. }\end{array}$ Asphyxia secondary to aspiration pneumonitis showed a negative but non-significant correlation with (Spearman's rho -0.0826, Prob $>|t|$ 0.7080). Table 3.

\section{DISCUSSION}

\subsection{General prevalence of amyloidosis}

In our study, the general prevalence of amyloidosis was found to be $13 \%$. This was generally high compared to many previous studies. For instance, James and Owor, (1975) carried out a study in mulago hospital, Kampala in which they analysed autopsy records for a 23 -year period (1951 to 1973) and their prevalence of amyloidosis was 0.57\%. In addition, a study of 6431 postmortems in northern India by Chugh (1981) showed a prevalence of amyloidosis to be $1.01 \%$. Similarly, Zegri-reiriz et al., (2019) reported a prevalence of 5.5\% among patients with Carpal tunnel syndrome. In Korea, the prevalence of amyloidosis was reported to be $0.93 \%$ (11), which was very low compared to our finding. It is worth noting that countries like Uganda with endemic infectious diseases such as tuberculosis and auto inflammatory diseases are assumed to have a higher chance of developing amyloid diseases. Infectious diseases are associated with pro-inflammatory mediators which can cause the liver and other sites to produce Serum Amyloid A (SAA) protein. This acute phase protein may ultimately deposit in the kidney leading to amyloidosis $(12,13)$ which may manifest in form of hepatomegaly, renal insufficiency and nephrotic syndrome or gastrointestinal disease (14).

However, some other researchers found relatively high prevalence of amyloidosis, for example Bassiouni et al., (2019) reported a $13.3 \%$ prevalence which is attributed to the fact that the study population was rheumatoid arthritis patients who had the disease for longer than 5 years and an elevated level of SAA. Maurizi et al., (2019) also reported a high prevalence of $9 \%$ in a study population of 343 hypertrophic cardiomyopathy (HCM) patients. HCM is associated with mutations in a gene that encodes proteins which may result in deposition of these mutated proteins in heart muscle as amyloid (16).

The mean age of amyloid positive cases was 61.67 years. These findings are close to those in a study that was carried out in Sweden among the 1,430 amyloidosis patients identified between 1995 and 2013, where the mean age of amyloid positive cases was 66 years (17). Seo et 
al., (2017) emphasised the fact that the prevalence of amyloidosis is much higher in patients older than 65years of age and those between 45 and 64, but less in those 20 and 44 years of age. Ternacle et al., (2019) precisely stated that cardiac amyloidosis increases with age among patients with cardiac stenosis.

\subsection{Prevalence by organ and gender}

According to James \& Owor, (1975), the kidney is most frequently involved in amyloidosis and its deposition is usually heavy. Similarly, in our study, $13 \%$ of the bodies had amyloid deposits in the kidney. In fact, Engineer et al., (2018) states that the kidney is the most affected organ as a result of systemic amyloidosis and most patients suffer from nephrotic syndrome.. However, Hassen et al., (2019) studied patients in South Africa, most of whom having nephrotic syndrome, and found out that the prevalence of renal amyloidosis was $1.38 \%$. Therefore it is of monumental importance for a clinician to suspect amyloidosis whenever a patient presents with nephrotic range proteinuria (Gertz et al., 2002).

The negative charge and high glycosaminoglycan content of the glomerular basement membrane and the presence of certain proteases that could cause abnormal folding of protein or affect stability of amyloid deposits might also promote amyloid formation in the kidney. HDL catabolism majorly happens in the kidney and Apolipoprotein AI is the major apolipoprotein of HDL. This increases the possibility of amyloid formation from amyloidogenic Apolipoprotein AI variant especially when it is present in high concentrations in the kidney. The high urea content and acidic $\mathrm{pH}$ of the kidney medulla are also potential predisposing factors for amyloid deposition in the kidney (23).

In our study, prevalence of amyloidosis was found to be higher in males (66.67\%) than females (33.3\%); These findings are similar to several previous studies, for instance, Hemminki et al., (2012) enrolled 813 amyloidosis patients between 2001 and 2008, where men had a 1.3 times higher incidence of the amyloidosis in men than women. Similarly Weiss et al., (2016) showed that 59\% of the 1,430 amyloidosis patients identified between 1995 and 2013 were men. However, Seo et al., (2017) reported that the prevalence of amyloidosis is the same among men and women. 


\subsection{Correlation between amyloidosis and cause of death}

We did not find any significant correlation between cause of death and amyloidosis. However, previous studies have reported otherwise. For instance, Hassen et al., (2019) reported amyloidosis in renal biopsies, whose major clinical diagnosis had been nephrotic syndrome. Engineer et al., (2018), through a retrospective study, also profiled patients with renal amyloidosis and reported that most of them had nephrotic syndrome, renal failure and TB. Other studies have reported that kidney as well as the heart are most common comorbidities involved in amyloidosis although the nervous and gastrointestinal systems are also implicated (25-29).

\subsection{Limitations}

Few post mortems were done at the Regional Referral hospital mortuary during the study period. Due to COVID-19 pandemic that led to closure of the university in March, our time frame was affected.

\section{CONCLUSION}

In our study, all the investigated body organs revealed amyloid in the kidney. We determined the prevalence of amyloidosis which was found to be $13 \%$. The prevalence of amyloidosis was more in men than in women.

There was no significant correlation between cause of death and amyloidosis.

\section{LIST OF ABBREVIATIONS}

AA: Amyloid A amyloidosis; A $\beta$ : Amyloid- $\beta$ peptide; AD: Alzheimer's disease; AL: Light chain Amyloidosis; DRA: Dialysis-Related Amyloidosis; FRC: Faculty of medicine Research Committee; GI: Gastrointestinal; Ig: Immunoglobulin; MLS: Medical Laboratory Science; MRRH: Mbarara Regional Referral Hospital; NS: Nervous system; SAA: Serum Amyloid-A protein; SAP: Serum Amyloid P; APOE: Apolipoprotein E; APOA1: Apolipoprotein A1; COVID-19: Corona Virus Disease-2019; SOP: Standard operating procedure.

\section{DECLARATIONS}

\section{Ethics approval and consent to participate}

Approval to carry out the study was given by the Department of Medical Laboratory Science and the Faculty Research Committee of Mbarara University of Science and Technology. 
Clearance was also sought from the Department of Pathology of Mbarara Regional Referral Hospital before commencement of the study.

\section{Consent for publication}

Not applicable

\section{Availability of data and materials}

The datasets used and/or analysed during the current study are available from the corresponding author on reasonable request.

\section{Competing interests}

The authors declare that they have no competing interests. There is no financial or personal relationship(s) that may have inappropriately influenced them in writing this article.

\section{Funding}

The authors received no financial support for the research, authorship, and/or publication of this article.

\section{Authors' contributions}

KJM, MJB, MFB, MK, GI: Perceived the concept, drafted a proposal, and designed the study protocol and data collection tool. Wrote the analysis plan and implemented the protocol. Took part in quality assurance of the study and laboratory work. Cleaned and analyzed data, and drafted and revised the paper. Met all the financial requirements of the study.

RA: Provided clearance for the study to be carried out in the pathology department of MRRH and technical guidance on slide examination. Contributed to drafting of the final paper.

BA: Provided guidance in concept development laboratory methods employed in Amyloidosis testing. Coordinated study processes within the pathology department.

BP: Provided technical guidance on logistics and laboratory methods employed in Amyloidosis testing. Provided supervision and technical support that was required for recruitment of study participants as well as collection of specimens in the post mortem of MRRH. 
SF: Assisted in concept development and guided the entire research team on data analysis, interpretation and presentation. Guided the overall preparation of the final report of the study.

All authors read and approved the final manuscript.

\section{ACKNOWLEDGEMENTS}

We extend our sincere appreciation to our supervisor; Mr. Ssedyabane Frank for guiding us through this research project.

We also thank the Faculty of Medicine Research Committee for having approved our research proposal.

We are greatly indebted to the Medical Laboratory Science Department for the time and material support that enabled us carry out a meaningful and valuable project.

\section{DISCLAIMER}

The views and opinions expressed in this article are those of the authors and do not necessarily reflect the official policy or position of any affiliated agency of the authors. 


\section{Table 1: POPULATION CHARACTERISTICS}

\begin{tabular}{|c|c|c|c|}
\hline \multicolumn{2}{|c|}{ Characteristic } & \multirow{2}{*}{$\begin{array}{l}\text { Frequency }(\mathbf{n}) \\
09\end{array}$} & \multirow{2}{*}{$\begin{array}{l}\text { Percentage }(\%) \\
39.1\end{array}$} \\
\hline Age group & $50-59$ & & \\
\hline & $60-69$ & 11 & 47.8 \\
\hline & $70-79$ & 02 & 8.7 \\
\hline & $80-89$ & 01 & 4.3 \\
\hline \multirow[t]{2}{*}{ Gender } & Male & 18 & 78.3 \\
\hline & Female & 05 & 21.7 \\
\hline \multirow[t]{9}{*}{ Address } & Mbarara & 07 & 30.4 \\
\hline & Masaka & 01 & 4.3 \\
\hline & Ntungamo & 03 & 13.0 \\
\hline & Sheema & 02 & 8.7 \\
\hline & Rwampara & 02 & 8.7 \\
\hline & Rukungiri & 01 & 4.3 \\
\hline & Kiruhura & 01 & 4.3 \\
\hline & Isingiro & 04 & 17.4 \\
\hline & Ibanda & 01 & 4.3 \\
\hline \multirow[t]{14}{*}{ Cause of death } & Disseminated T.B & 01 & 4.3 \\
\hline & Hemmorrhagic shock & 01 & 4.3 \\
\hline & Lung failure & 02 & 8.7 \\
\hline & Secondary peritonitis & 02 & 8.7 \\
\hline & Not determined & 02 & 8.7 \\
\hline & Closed head injury & 01 & 4.3 \\
\hline & Neurogenic shock & 02 & 8.7 \\
\hline & Bronchial pneumonia & 04 & 17.4 \\
\hline & Sudden cardiac death & 01 & 4.3 \\
\hline & Asphyxia from drowning & 01 & 4.3 \\
\hline & Renal insufficiency & 01 & 4.3 \\
\hline & $\begin{array}{l}\text { Asphyxia secondary to } \\
\text { aspiration pneumonitis }\end{array}$ & 01 & 4.3 \\
\hline & Cerebral injury & 03 & 13.0 \\
\hline & $\begin{array}{l}\text { Asphyxia secondary to } \\
\text { strangulation }\end{array}$ & 01 & 4.3 \\
\hline
\end{tabular}


Table 2: PREVALENCE OF AMYLOIDOSIS

$\mathrm{N}=23$

\begin{tabular}{clll}
\hline Characteristic & Frequency (n) & Percentage (\%) \\
\hline General & 03 & 13.0 \\
Positive & & \\
Negative & 20 & 87.0 \\
& & \\
& Organ & & 0.0 \\
Amyloid present & Brain & 00 & 0.0 \\
& Heart & 00 & 0.0 \\
& Liver & 00 & 100.0 \\
& Kidney & 03 & \\
& Gender & & 66.7 \\
Male & 02 & 33.3 \\
\hline
\end{tabular}

Table 3: CORRELATION BETWEEN AMYLOIDOSIS AND CAUSE OF DEATH

\begin{tabular}{lllll}
\hline Cause of death & Congo red stain & $\begin{array}{l}\text { Spearman's } \\
\text { correlation }\end{array}$ \\
\hline & $\begin{array}{l}\text { Positive } \\
(\mathbf{n = 3})\end{array}$ & $\begin{array}{l}\text { Negative } \\
(\mathbf{n = 2 0})\end{array}$ & $\begin{array}{l}\text { Spearman' } \\
\text { s rho }\end{array}$ & $\begin{array}{l}\text { Prob } \\
\text { |t|t|}\end{array}$ \\
\hline Disseminated_T.B & 0 & 1 & -0.0826 & 0.7080 \\
Hemorragic_shock & 0 & 1 & -0.0826 & 0.7080 \\
Lung_Failure & 0 & 2 & -0.1195 & 0.5870 \\
Secondary_Peritonitis & 1 & 1 & 0.3386 & 0.1140 \\
Not_Determined & 0 & 2 & -0.1195 & 0.5870 \\
Closed_Head_Injury & 0 & 1 & -0.0826 & 0.7080 \\
Neurogenic_shock & 0 & 2 & -0.1195 & 0.5870 \\
Sudden_Cardiac_Death & 0 & 1 & -0.0826 & 0.7080 \\
Asphyxia_from_drownig & 0 & 1 & -0.0826 & 0.7080 \\
Renal_Insufficiency & 0 & 1 & -0.0826 & 0.7080 \\
Asphyxia_secondary_to aspiration pnuemonitis & 1 & 0 & -0.0826 & 0.7080 \\
Cerebral_Injury & 0 & 3 & -0.1500 & 0.4945 \\
Asphyxia_Secodary_to_Strangulation & 0 & 1 & 0.5505 & 0.0065 \\
Bronchopneumonia & 1 & 3 & 0.1629 & 0.4577 \\
\hline
\end{tabular}




\section{PHOTOMICROGRAPHS SHOWING AMYLOID IN KIDNEY GLOMERULI}

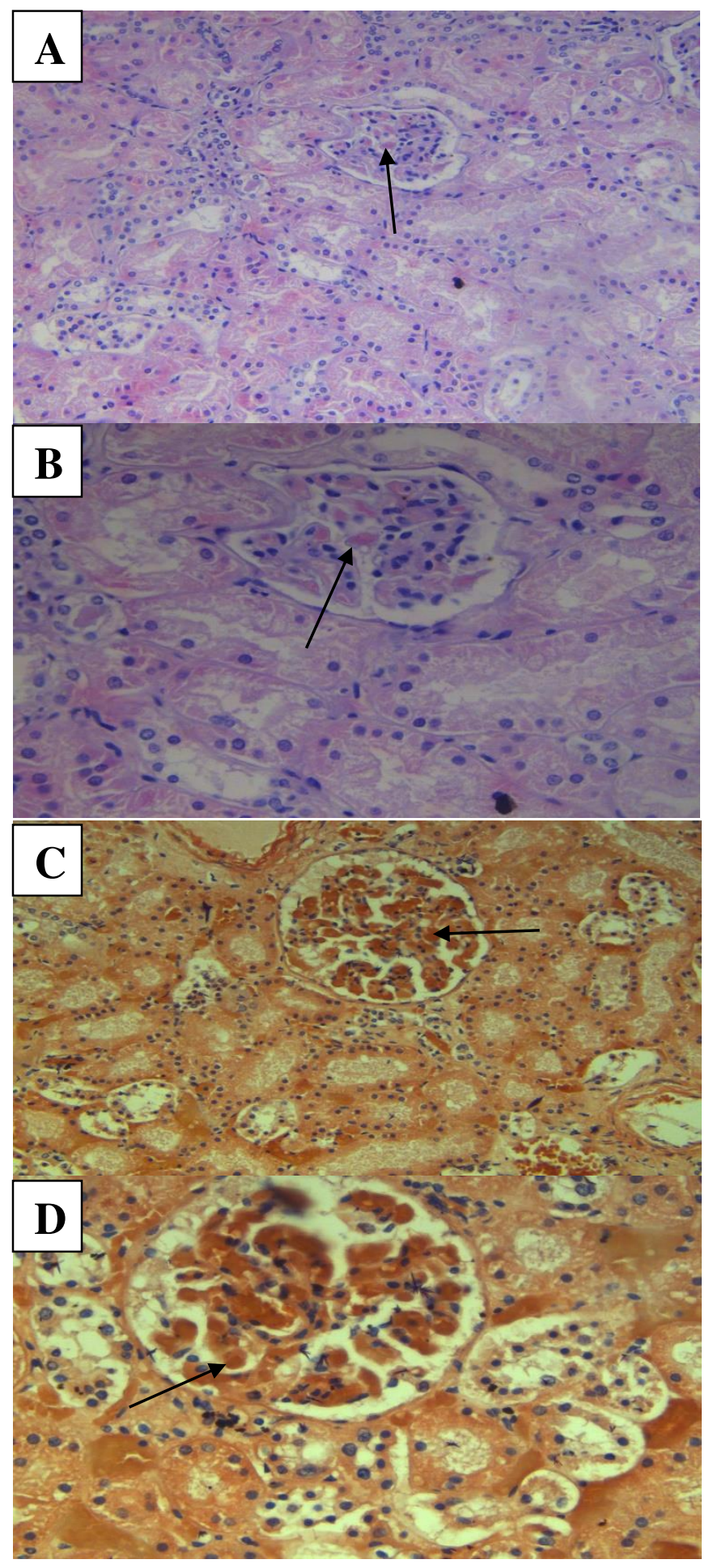

A: Haematoxylin and Eosin staining showing pink amorphous amyloid deposits in the glomerulus (200x);

B: Haematoxylin and Eosin staining showing pink amorphous amyloid deposits in the glomerulus (400x); C: Congo red staining showing pink amorphous amyloid deposits in the glomerulus (200x); D: Congo red staining showing pink amorphous amyloid deposits in the glomerulus (400x). 


\section{REFERENCES}

1. Tan SY, Pepys MB. Amy loidosis. 1994;

2. Bouke PC. RHEUMATIC DISEASE CLINICS OF NORTH AMERICA Amyloidosis : 2013;

3. Pepys MB. Amyloidosis. 2006;

4. Merlini G, Seldin DC, Gertz MA. Amyloidosis : Pathogenesis and New Therapeutic Options. 2011;29(14).

5. Kokong DD, Ibekwe TS, Okolo CA, Kodiya AM, Fasunla JA, Nwaorgu OGB, et al. Amyloid angiopathy of the floor of the mouth: A case report and review of the literature. J Med Case Rep. 2007;1:1-4.

6. Bassiouni H, El-Atrebi A, Abou-Gabal KZ and H. Prevalence of Subclinical Amyloidosis in a Cross-sectional Study of Egyptian RA Patients without Proteinuria. Vol. 15, Current Rheumatology Reviews. 2019. p. 162-7.

7. James ID, Owor R. VOL. 69. No. 5 \& 6. 1975. 1975;69(5):480-3.

8. Lavatelli F, Albertini R, Di Fonzo A, Palladini G, Merlini G. Biochemical markers in early diagnosis and management of systemic amyloidoses. Clin Chem Lab Med. 2014;52(11):1517-31.

9. Picken MM. Amyloidosis - Where Are We Now and Where Are We Heading? 2010;545-51.

10. Zegri-reiriz I, Moral FJDH, Dominguez F, Salas C, Cuadra P De, Plaza A, et al. Prevalence of Cardiac Amyloidosis in Patients with Carpal Tunnel Syndrome. 2019;

11. Seo SR, Jang SY, Lee GY, Choi B, Chun H, Cho EJ, et al. Prevalence of Amyloidosis in Korea. 2017;1-5.

12. Nienhuis HLA, Bijzet J, Hazenberg BPC. Systemic Amyloidosis : Review The Prevalence and Management of Systemic Amyloidosis in Western Countries. 2016;10-9.

13. Ramakant D, Rakesh G, Lokendra D, Nishi P, Sidharth S. Clinical profile of patients 
having pulmonary tuberculosis and renal amyloidosis. PMC. 2009;

14. Tank SJ, Chima RS, Shah V, Malik S, Joshi S, Mazumdar RH. Renal Amyloidosis Following Tuberculosis. 2000;67(2):679-81.

15. Maurizi N, Rella V, Fumagalli C, Salerno S, Castelletti S, Dagradi F, et al. Prevalence of cardiac amyloidosis among adult patients referred to tertiary centres with an initial diagnosis of hypertrophic cardiomyopathy. Int J Cardiol [Internet]. 2019;(xxxx). Available from: https://doi.org/10.1016/j.ijcard.2019.07.051

16. Flour IC, Congress C, Technologists C. Acoustic. 1998;116-25.

17. Weiss BM, Lund SH, Bjorkholm M, Cohen AD, Dember L, Landgren O, et al. Improved Survival in AL Amyloidosis: A Population-Based Study on 1,430 Patients Diagnosed in Sweden 1995-2013. 2016;

18. Ternacle J, Krapf L, Mohty D, Magne J, Nguyen A, Galat A, et al. Aortic Stenosis and Cardiac Amyloidosis. 2019;74(21).

19. Jack RJ, Wiste HJ, Weigand SD, Rocca WA, Knopman DS, Mielke MM, et al. Agespecifi c population frequencies of cerebral $\beta$-amyloidosis and neurodegeneration among people with normal cognitive function aged $50-89$ years : a cross- sectional study. 2014;997-1005.

20. Engineer DP, Kute VB, Patel H V, Shah PR. of Kidney Diseases and Transplantation Original Article Clinical and Laboratory Profile of Renal Amyloidosis : 2018;29(5):106572.

21. Hassen M, Bates W, Moosa MR. Pattern of renal amyloidosis in South Africa. 2019;1-9.

22. Gertz MA, Martha QL, Dispenzieri A. Immunoglobulin light chain amyloidosis and the kidney. Immunoglobulin Light Chain amyloidosis kidney. 2002;61:1-9.

23. Dember LM. \$ Amyloidosis-Associated Kidney Disease. 2006;12.

24. Hemminki K, Li X, Försti A, Sundquist J, Sundquist K. Incidence and survival in nonhereditary amyloidosis in Sweden. 2012;

25. Wechalekar AD, Gillmore JD, Hawkins PN. Systemic amyloidosis. Lancet [Internet]. 
2015;6736(15):1-14. Available from: http://dx.doi.org/10.1016/S0140-6736(15)01274-X

26. Gillmore JD, Stangou AJ, Lachmann HJ, Goodman HJ, Wechalekar AD, Acheson J, et al. Organ Transplantation in Hereditary Apolipoprotein.

27. Lachmann HJ, Hawkins PN. Systemic amyloidosis. 2006;214-20.

28. Smits P, Thien T, Erkelens DW, Romijn JA. Editor in chief. 2004;62(4).

29. Dubrey SW, Hawkins PN, Falk RH. Education in Heart Amyloid diseases of the heart: assessment, diagnosis, and referral. 2011; 